\title{
Acute pain management in children
}

\author{
This article was published in the following Dove Press journal: \\ Journal of Pain Research \\ 12 July 2010 \\ Number of times this article has been viewed
}

\section{Susan T Verghese \\ Raafat S Hannallah \\ The George Washington University Medical Center, Division of \\ Anesthesiology, Children's National \\ Medical Center, Washington, DC, USA}

Correspondence: Susan TVerghese Division of Anesthesiology, Children's National Medical Center, I I I Michigan Avenue, N.W.,Washington, DC, USA

Tel + I 2024762025

Email sverghes@cnmc.org
Abstract: The greatest advance in pediatric pain medicine is the recognition that untreated pain is a significant cause of morbidity and even mortality after surgical trauma. Accurate assessment of pain in different age groups and the effective treatment of postoperative pain is constantly being refined; with newer drugs being used alone or in combination with other drugs continues to be explored. Several advances in developmental neurobiology and pharmacology, knowledge of new analgesics and newer applications of old analgesics in the last two decades have helped the pediatric anesthesiologist in managing pain in children more efficiently. The latter include administering opioids via the skin and nasal mucosa and their addition into the neuraxial local anesthetics. Systemic opioids, nonsteroidal anti-inflammatory agents and regional analgesics alone or combined with additives are currently used to provide effective postoperative analgesia. These modalities are best utilized when combined as a multimodal approach to treat acute pain in the perioperative setting. The development of receptor specific drugs that can produce pain relief without the untoward side effects of respiratory depression will hasten the recovery and discharge of children after surgery. This review focuses on the overview of acute pain management in children, with an emphasis on pharmacological and regional anesthesia in achieving this goal.

Keywords: pediatric pain treatment, pain medication in children, pediatric regional anesthesia, pca and pcea in children, epidural additives

\section{Introduction}

The practice of pediatric pain management has made great progress in the last decade with the development and validation of pain assessment tools specific to pediatric patients. Prior to that, adequate assessment and treatment of pediatric pain lagged behind that of adult analgesia due to a lack of clinical knowledge, insufficient pediatric research, and the fear of opioid side effects and addiction. The guidelines provided by organizations such as the American Pain Society (APS) and the Agency for Health Care Research and Quality (ARQ), as well as mandates issued by the Joint Commission on Accreditation of Healthcare Organizations (JCAHO) led to the inclusion of pediatric analgesic trials to provide evidence-based pain management guidelines in children of all ages. Almost all the major children's hospitals now have dedicated pain services to provide evaluation and immediate treatment of pain in any child. A multimodal approach to preventing and treating pain is usually used. Mild analgesics, local and regional analgesia, together with opioids when indicated, are frequently combined to minimize side effects of individual drugs or techniques. 


\section{Pain assessment}

The ability to assess pain in children appropriately by using standardized pain scores has improved the clinician's ability to treat postoperative pain in children over the past few years. Children suffer postoperative pain in the same way as adults. The main difference is that factors such as fear, anxiety, coping style and lack of social support can further exaggerate the physical pain in children. The analgesic requirement following surgery does not depend on the age of the patient but on the nature of the procedure and the pain threshold of the patient. Pain assessment is a critical component of pain management in any patient. A full description of the different ways to assess pain in children is available in text books which detail pediatric pain treatment in both the acute and chronic setting. ${ }^{1}$ However, assessing pain in young children can be challenging if they are nonverbal or have developmental disabilities. The perception and communication of the child's pain depends on his or her intellectual and social development. Expression of pain therefore relies on the child's ability to understand, quantitate and communicate it. Self-reporting which is the "gold standard" for assessment is possible only in older children or those with cognitive and communicative abilities. Adult scales have been modified and converted to a simple format to enable the child to understand and quantify pain. Selfreporting scales require that a child has the cognitive ability to pinpoint the degree of pain on a relative scale. In the last decade, a variety of tools to assess pain and age appropriate pain assessment scales have become clinically available to provide qualitative and quantitative information as well as the documentation of pain. At the Children's National Medical Center, Washington, DC different pain scales are used to assess pain in children. Our post anesthesia care unit (PACU) record requires the assessment and documentation of pain scores for each patient on arrival; every time that vital signs are recorded and prior to discharge to the floor. ${ }^{2}$ (Figures 1 and 2) The measurements of pain in newborns, infants, young children, and children with developmental disabilities who are unable to self-report have also undergone major improvements. There are numerous clinical practice guidelines and policy statements that have been published on pediatric pain. ${ }^{3}$

Behavioral measures of pain include behavior checklists that provide a list of pain behaviors that are looked for, and if present, a numerical score is given. The total number of behaviors that are present in the child are then used to estimate his/her pain at the time of assessment. Irrespective of the tool selected, assessment of postoperative pain is greatly facilitated by introducing the concept of pain rating and of the tool itself during the preoperative preparation of the child. These pain assessment tools may facilitate reliable and valid observational pain assessment in children with cognitive impairment who cannot self-report their pain. Objective pain assessment is important to facilitate effective postoperative pain management in these vulnerable children. ${ }^{4}$

Perioperative pain management therefore begins during the preoperative visit by preparing both the parent and the child about the upcoming surgery and information about the type of pain that is associated with it. The knowledge regarding the different types of drugs, blocks, and their effectiveness, as well as the side effects must be conveyed to the parent prior to surgery. The type of analgesia that will be a part of the anesthetic plan should be shared with the family particularly if the plan is to use a single-dose regional technique, continuous epidural catheter technique, or patient controlled analgesia (PCA). The current trend is to provide preemptive regional blocks before surgery, after anesthetic induction, as well as postoperative local infiltration of the wound, in an attempt to lessen the need for narcotics during recovery. An ideal way to provide better postoperative analgesia in children is the use of multiple analgesics with additive or synergistic effects, yet with different side effect profiles so that adequate analgesia can be provided with the least amount of side effects. Moderate to severe pain in any patient is best treated with a combination of analgesic techniques. Pain can be treated at the peripheral level using local anesthetics, peripheral nerve blockade, nonsteroidal anti-inflammatory drugs (NSAIDs), or opioids. At the brain level it can be treated with local anesthetics, opioids, and $\alpha_{2}$ agonists.

\section{Pharmacological interventions Nonopioid analgesics}

Acetaminophen (Paracetamol), Ibuprofen, Naproxen, Diclofenac, and Ketorolac are the nonopioid analgesics that are available for the treatment of pain. When used alone, they are adequate to treat mild pain although they need to be combined with other agents for treating moderate to severe pain. These drugs have a ceiling effect and are best used in combination with opioids to decrease the dose of the opioids and thus their side effects.

\section{Acetaminophen}

Acetaminophen is an antipyretic with weak analgesic properties. It exerts the antipyretic effect at the hypothalamus and the analgesic effects by blocking central prostaglandin 


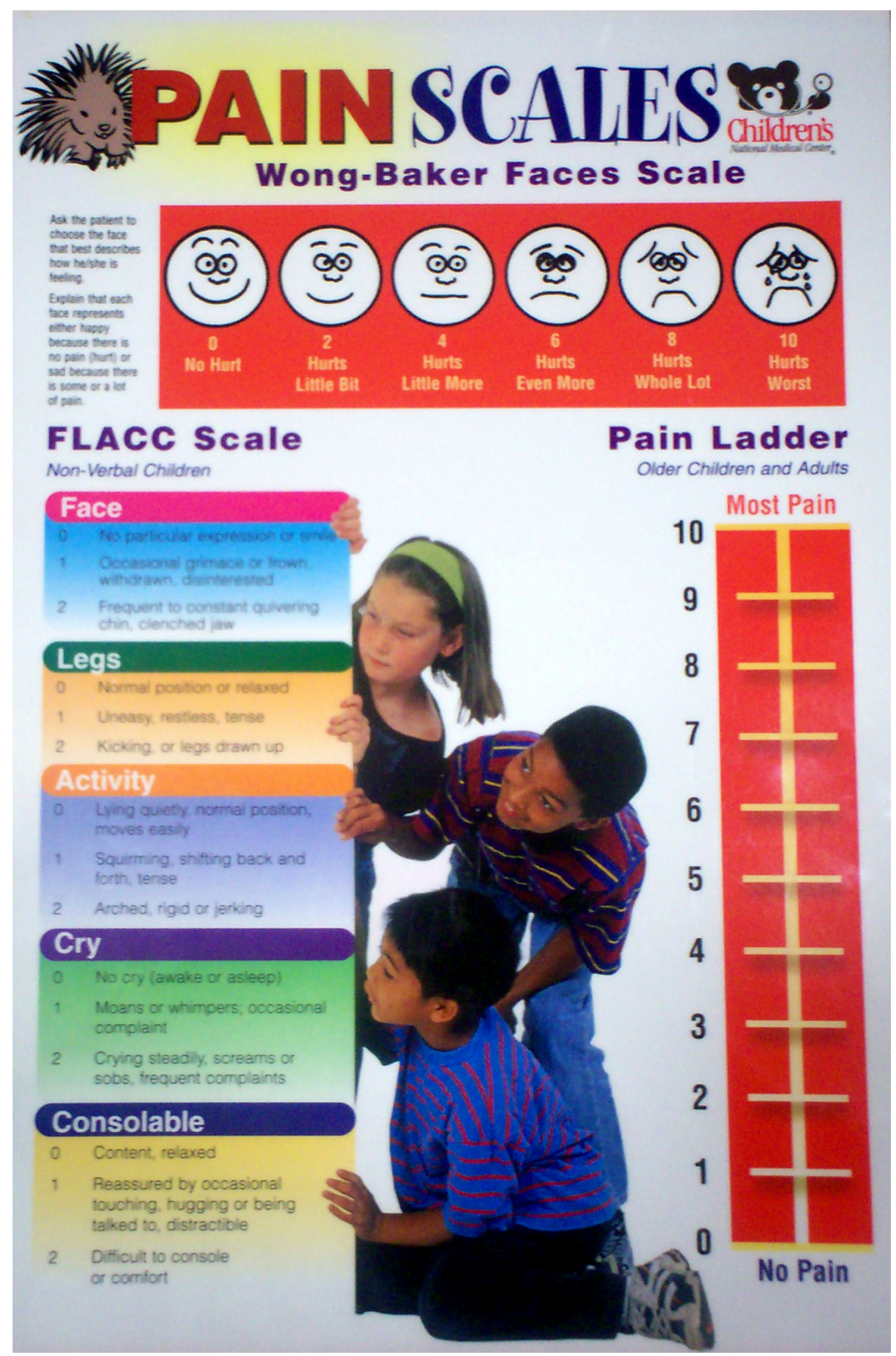

Figure I Pain Scales.

Notes: At Children's National Medical Center (CNMC), Staff have a choice among three different scales to assess a child's pain. The Objective Pain Scale (OPS) is used for children up to 3-years of age or nonverbal children. The Wong-Baker Faces Rating Scale is used for persons age 3 and over, and the Lineal Analog Pain Scale is used for older children and adolescents.

synthesis, reducing substance P-induced hyperalgesia, and modulating the production of hyperalgesic nitric oxide in the spinal cord. ${ }^{1}$ Pharmacokinetic studies have changed the traditional dosing guidelines for acetaminophen in children. ${ }^{5}$ The initial dose is up to $45 \mathrm{mg} / \mathrm{kg}$ administered rectally before awakening from anesthesia. ${ }^{6}$ Additional doses can be given orally (10-15 $\mathrm{mg} / \mathrm{kg}$ ) or rectally $(20 \mathrm{mg} / \mathrm{kg})$ round the clock (RTC) every 4-6 hours (and not as needed) to produce analgesia with the maintenance of an adequate blood level of $10-20 \mathrm{mcg} / \mathrm{mL} .^{7}$ The total daily dose of acetaminophen, via any route, should not exceed: $100 \mathrm{mg} / \mathrm{kg}$ for children; $75 \mathrm{mg} / \mathrm{kg}$ for infants; $60 \mathrm{mg} / \mathrm{kg}$ for term and preterm neonates 


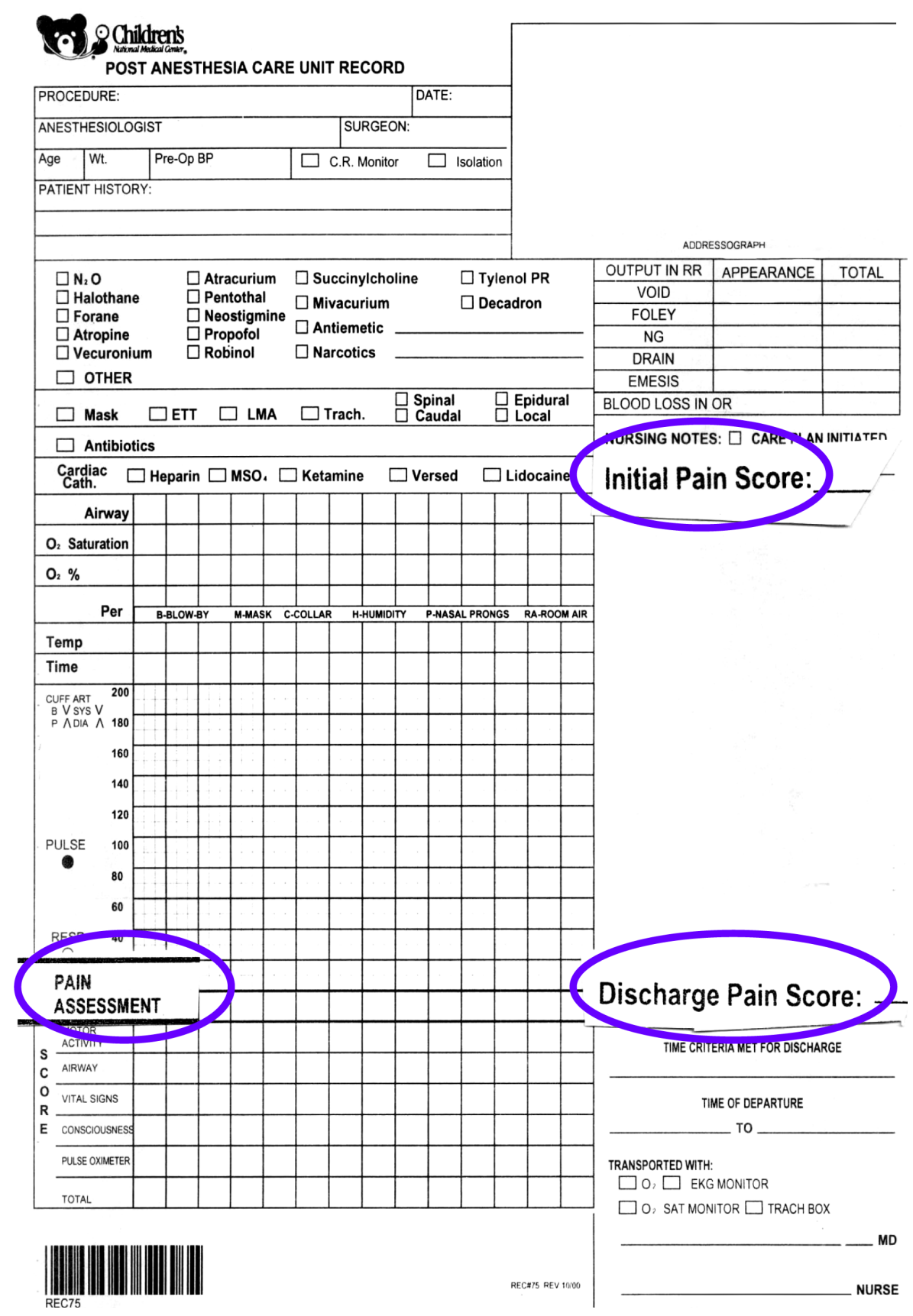

Figure 2 PACU record at CNMC.

Notes: Pain is assessed and a Pain Score documented when the child arrives in PACU (A), upon discharge (B), and every time vital signs are recorded (C). Similar assessments and documentation are made on the Pediatric Flow Sheet for in-patients at minimum every 8-hour shift.

Abbreviations: CNMC, Children's National Medical Center; PACU, post anesthesia care unit.

older than 32 weeks post conceptual age; and $40 \mathrm{mg} / \mathrm{kg}$ for preterm neonates younger than 32 weeks post conceptual age. ${ }^{8}$ Studies in children undergoing tonsillectomy and cleft palate repair however did not show an analgesic value of the recommended doses of acetaminophen. ${ }^{9}, 10$

Acetaminophen may be combined with codeine for more effective control of moderately severe pain and/or discomfort. Acetaminophen with codeine elixir contains $120 \mathrm{mg}$ acetaminophen and $12 \mathrm{mg}$ codeine per $5 \mathrm{~mL}$. The usual dose is $5 \mathrm{~mL}$ for children $3-6$ years, and $10 \mathrm{~mL}$ for the $7-12$ age group. ${ }^{11}$ This combination is also available as tablets Tylenol 1, 2, 3, and 4 - the number referring to the quantity of codeine in each tablet ( $\mathrm{T} 1 \mathrm{has} 7.5 \mathrm{mg}$ codeine, $\mathrm{T} 2$ has $15 \mathrm{mg}$ codeine, T3 has $30 \mathrm{mg}$ codeine and T4 has 
$60 \mathrm{mg}$ codeine). Hepatotoxicity has been reported with doses of acetaminophen only slightly above the recommended 10 - to $15 \mathrm{mg} / \mathrm{kg} /$ dose orally for a total of five doses or 50 to $75 \mathrm{mg} / \mathrm{kg} /$ day, suggesting that acetaminophen may have a narrow therapeutic index. ${ }^{12}$

A study comparing rectal and intravenous administration of therapy with acetaminophen showed that rectal acetaminophen $40 \mathrm{mg} / \mathrm{kg}$ provided longer analgesia for moderately painful procedures when compared with $15 \mathrm{mg} / \mathrm{kg}$ acetaminophen administered intravenously. ${ }^{13}$

Acetaminophen is available in a wide variety of oral formulations alone or in combination with decongestants in cold remedies and with opioids for the treatment of moderate to severe pain. The wide range of over the-counter acetaminophen-containing products poses a potential risk of overdosing children who may be given more than one formulation that contains the drug. Parental education as well as frequent review of the patient's medications is needed to minimize the risk of overdose.

\section{Nonsteroidal anti-inflammatory drugs (NSAIDs)}

NSAIDs inhibit the enzyme cyclooxygenase (COX), reduce the production of prostaglandins at the site of tissue injury, and diminish the inflammatory cascade.

The COX-1 enzyme is present in the brain, gastrointestinal tract, kidneys, and platelets and preserves gastric mucosal integrity and function, platelet aggregation, and renal perfusion. Blocking the COX-1 enzyme therefore can result in injury to gastric mucosa, platelet dysfunction and decrease renal perfusion. COX-2 expression is induced by inflammation or tissue injury.

Selective COX-2 inhibitors reduce inflammation although they have less effect on gastric mucosal function and have fewer effects on platelet aggregation, thereby resulting in fewer side effects. The development of selective Cyclooxygenase (COX-2) inhibitors that can alleviate pain and inflammation without inhibiting the platelet function (mediated by the COX-1-derived prostanoids) appears to be an ideal way to treat pain in pediatric patients. A study evaluating the analgesic effectiveness of acetaminophen combined with either ibuprofen or rofecoxib showed that the addition of ibuprofen although not rofecoxib, reduced the need for early analgesia following tonsillectomy by $50 \%$ when compared to acetaminophen alone. ${ }^{14}$ Another study that evaluated 66 children, aged 3-11 years-of-age, scheduled to undergo tonsillectomy, found that a single preoperative dose of rofecoxib $(1 \mathrm{mg} / \mathrm{kg})$ resulted in less vomiting and lower 24-hour pain scores in pediatric patients undergoing an elective tonsillectomy. ${ }^{15}$ In addition to their peripheral effects, the NSAIDs have also been shown to exert a direct spinal action by blocking the hyperalgesic response induced by activation of spinal glutamate and substance P receptors. ${ }^{16}$ Diclofenac provides effective analgesia after minor surgical procedures in children. The pediatric dose of diclofenac is $1 \mathrm{mg} / \mathrm{kg}$ every 8 hours orally, rectally, or intravenously. It is available only as an oral tablet in the United States, although it is available as a suppository and in the injectable form in several countries. When diclofenac was administered rectally, the relative bioavailability was greater and the peak concentration was reached earlier than after oral administration. ${ }^{17}$

Among the nonselective NSAIDs, Ketorolac Tromethamine is still the only intravenous (IV) form of NSAID available in the United States. Optimal postoperative analgesia is possible if the drug is given early, immediately following induction, since the onset of pain relief is 20 to 30 minutes following its administration. The analgesic and opioid-sparing effects of ketorolac, which may reduce the incidence of opioid-related adverse effects such as respiratory depression, nausea and vomiting, have been demonstrated by numerous studies in children. ${ }^{18}$ A recent study in young children treated with ketorolac alone after minimally invasive open ureteroneocystostomy with a small incision showed that it was associated with a short length of stay and low pain scores. ${ }^{19}$ Intravenous ketorolac $(0.5 \mathrm{mg} / \mathrm{kg})$ has also been shown to reduce the frequency and severity of postoperative bladder spasms after ureteral reimplant procedures in children. ${ }^{20}$ These spasms can be extremely uncomfortable, can occur in spite of a regional analgesic blockade, and are poorly treated with most opioid analgesics. Ketorolac appears to suppress bladder contractions and increase bladder capacity by lowering bladder prostaglandin levels, thereby reducing the C-fiber mediated bladder pain and hyperactivity.

The untoward side effects of Ketorolac include decreased bone repair after osteotomy, bronchospasm, acute renal failure and possibly increased surgical bleeding secondary to altered platelet function. ${ }^{21}$ Earlier studies have reported an increased incidence of bleeding in patients who received ketorolac following tonsillectomy. ${ }^{22,23}$ A quantitative systemic review of 25 studies examined the risk of bleeding after tonsillectomy when NSAIDs were used in 970 patients. Of the four bleeding end points, namely, blood loss, postoperative bleeding, hospital admission, and re-operating because of bleeding, only re-operation happened significantly more frequently with NSAIDs. Compared to opioids, NSAIDs were equianalgesic, with less risk of postoperative nausea and vomiting (PONV). ${ }^{23}$ 


\section{Dextromethorphan}

Dextromethorphan is a weak N-methyl-d-aspartate (NMDA) receptor antagonist that inhibits spinal cord sensitization in animal models of pain as well as the development of cutaneous secondary hyperalgesia after tissue trauma. Dextromethorphan is an antitussive ingredient, and an isomer of the codeine analog levorphanol with an analgesic effect via the noncompetitive NMDA receptor antagonism. The efficacy of the preoperative use of dextromethorphan for control of post-adenotonsillectomy pain is controversial. Dawson and colleagues reported a $34 \%$ reduction in the need for intravenous (IV) morphine during the first 6 hours after surgery in children who received a single $1 \mathrm{mg} / \mathrm{kg}$ dose of dextromethorphan preoperatively. ${ }^{24}$ However; there was no difference in oral analgesic consumption or type of diet tolerated from controls beyond 6 hours. Rose and colleagues however could not duplicate the reported efficacy of dextromethorphan in reducing post-adenotonsillectomy pain in patients who received preoperative morphine and acetaminophen analgesia. ${ }^{25}$ Another study where oral dextromethorphan cough syrup $(1 \mathrm{mg} / \mathrm{kg})$ given preoperatively was compared to intravenous tramadol $(1 \mathrm{mg} / \mathrm{kg})$ given after induction of anesthesia. The latter was found to be more effective in reducing post-tonsillectomy pain in children. ${ }^{26}$ The lack of activity at the mu-receptors, and thus the lack of undesirable opioid side effects such as respiratory depression, and PONV is the most desirable feature of this drug.

\section{Tramadol}

Tramadol is a synthetic analog of codeine, although it is not a controlled drug. It is an analgesic agent with medium potency. It is a unique drug with two complementary mechanisms of action. One of its metabolites has a weak affinity for the mu-opioid receptors without any affinity for the two delta or kappa receptors. The second mechanism is its ability to inhibit the reuptake of the neurotransmitters norepinephrine and serotonin. Tramadol causes less sedation compared to other opioids with minimal effects on respiration which is an advantage over the opioid analgesics used for postoperative pain relief in children. A study with oral tramadol in children demonstrated a dose-ranging effect, with patients receiving a $2 \mathrm{mg} / \mathrm{kg}$ dose requiring $42 \%$ less rescue analgesics than those who received a $1 \mathrm{mg} / \mathrm{kg}$ dose. ${ }^{27} \mathrm{An}$ intravenous dose of tramadol $1-2 \mathrm{mg} / \mathrm{kg}$ has been shown to be a suitable alternative to intravenous morphine in post-tonsillectomy patients..$^{28}$ The most troubling side effect of tramadol is the increased incidence of PONV, (9\%-10\%) pruritus (7\%) and rash (4\%). This is more likely with postoperative oral administration than with intraoperative IV use. Tramadol also has a distinct advantage over NSAIDS because of its lack of inhibition on prostaglandin synthesis. Oral tramadol has been shown to have the same analgesic efficacy as oral diclofenac for post-tonsillectomy pain in patients 11 years and older, without the side effects of NSAIDs. ${ }^{29}$ It is important to note that the use of ondansetron to treat PONV results in the inhibition of tramadol analgesia probably due to a reduction of binding to the $5-\mathrm{HT}_{3}$ receptors at the spinal level. ${ }^{30}$ Tramadol is currently available in a tablet form alone or in combination with acetaminophen in the USA. Its availability in other countries as an injectable form, liquid form and suppository form provides more flexibility in using this drug in the perioperative period. It is best used as an analgesic supplement to treat mild to moderate pain because of it opioid sparing effect and low incidence of side effects.

\section{Opioid analgesics}

The word "opium" is derived from the Greek word meaning juice and refers to the juice of the poppy plant. Opioids exert their effects similarly to the endogenous opioid peptides met-enkephalin, beta-endorphin, and dynorphin which act at specific opioid receptors. These opioid receptors are found in the presynaptic and postsynaptic sites in the brain, spinal cord, and peripheral nerve cells. The activation of these different receptors in the central nervous system (CNS) namely, mu, kappa, delta, and sigma causes neuronal inhibition by decreasing the release of excitatory neurotransmitters from the presynaptic terminals. The drugs that act by exerting their effects on opioid receptors are classified as agonists, antagonists, partial agonists and mixed agonist-antagonists.

A clear knowledge of the type of opioid receptor that is being activated and the effect of stimulating or blocking each is important to the clinician before prescribing these drugs and the drugs to reverse their action should the need arise. Mu receptors are present as two types: mu1, when activated produce supraspinal analgesia and physical dependence; mu 2 receptors are responsible for respiratory depression, bradycardia, physical dependence, and gastrointestinal dysmotility. Morphine, codeine, hydromorphone, fentanyl, sufentanil, alfentanil, meperidine and methadone are some of the agonist drugs that are commonly used by the anesthesiologists in acute pain management.

The activation of the other receptor kappa causes analgesia without significant respiratory depression and the drugs that act on these receptors are dynorphin, pentazocine, butarphanol, nalbuphine, buprenorphine, and nalorphine. The activation of the sigma receptors produces dysphoria, hypertonia, 
tachycardia, tachypnea and mydriasis. Pentazocine and ketamine are 2 agonist drugs that act on the sigma receptors. The effect of the drugs at the mu, delta, and kappa receptors can all be reversed by naloxone, an antagonist that simply binds to these receptors and block the effect of the agonist. There are partial agonists that act with reduced intrinsic activity thus producing less than a maximal response and mixed agonist and antagonists that act as agonists at certain opioid receptors and as antagonists at the other. ${ }^{1}$

A short acting drug is usually chosen when opioids are indicated in the immediate recovery period. Intravenous use allows more accurate titration of the dose and avoids the use of "standard" dosages based on weight, which may lead to under-medication or relative overdose. Fentanyl, up to a dose of $2 \mu \mathrm{g} / \mathrm{kg}$, is the drug of choice for intravenous use. In the absence of an intravenous route, meperidine $(0.5 \mathrm{mg} / \mathrm{kg})$ and codeine $(1.0-1.5 \mathrm{mg} / \mathrm{kg})$ can be used intramuscularly. Intramuscular (IM) codeine tends to result in less vomiting than other opioids, especially morphine. ${ }^{31}$ However, children are so fearful of IM injections that they often will deny pain to avoid the therapeutic and equally painful injection. Other novel routes of administration like the nasal administration of fentanyl has been shown to result in an analgesic blood level comparable to that following IV use, making it useful in children who do not have, or have lost, their IV access. ${ }^{32,33}$

It is very important to exercise caution when opioids are used in neonates and young infants. They have increased susceptibility to apnea because of the relative imbalance of mu 1 (analgesia) to mu 2 (respiratory depression) receptors. They also have increased susceptibility to hypoventilation because of a decreased ventilatory response to hypoxia and hypercapnea. Due to their immature liver conjugation (glucuronidation, sulfation, and oxidation) and immature renal filtration, the metabolism and excretion of opioids and their metabolites are markedly decreased. In addition, there is a higher concentration of the drug in the brain because of an immature blood-brain barrier. Newborns and young infants less than 4-6 months of age also have increased free fraction of the drug in the blood because of decreased plasma protein (less alpha-1 acid glycoprotein and albumin) binding.

Codeine, Oxycodone (Tyelox, Percocet) and hydrocodone (Vicodin, Loratab) are opioids used when parenteral opioids need to be converted to enteral ones. These have a $60 \%$ bioavailability after oral ingestion. The analgesic effects occur 20 minutes after ingestion and reach a maximum by 60-120 minutes. Only 10\% of the codeine is metabolized into morphine and this portion is responsible for the analgesic effect of codeine. Usual dose is $0.5 \mathrm{mg}$ to $1 \mathrm{mg} / \mathrm{kg}$ of codeine.
When opioids are administered as boluses, there are always break through periods of pain between the peaks and troughs of analgesic levels. An optimal way to avoid the most serious complication of opioid therapy, the respiratory depression and apnea is to titrate the drug slowly in divided doses and to monitor the respiratory rate carefully by clinical observation as well as by setting the alarm limits on the respiratory rate in the patient's monitor. The ability to treat apnea by assisting or controlling ventilation by bag and mask ventilation and availability of intravenous naloxone to reverse the ventilatory depression must accompany any opioid therapy. It is also important to have a functioning suction at hand because of the high possibility of nausea and vomiting following the administration of single boluses of narcan. Other unwanted effects of giving narcan administration are tachycardia, hypertension and occasionally pulmonary edema. Younger children develop a tolerance to opioids and benzodiazepines more rapidly than older children. The management of tolerance and withdrawal has now become a nearly universal consequence of prolonged administration of these medications to critically ill neonates, infants, and children.

\section{Intravenous patient controlled analgesia in children}

Intravenous patient-controlled analgesia (IV-PCA) is one of the most effective methods to achieve optimal postoperative analgesia in adults and children. IV-PCA provides effective pain treatment, adjusts the dose according to individual needs, and allows the patients to be in control of their pain management decisions. The use of this technique has expanded to even young children. Not only does IV-PCA provide consistent opioid blood levels, it also spares children the pain of IM injections that used to be routinely used for postoperative opioid administration.

An appropriate IV opioid loading dose to initiate adequate analgesia is necessary when planning an IV-PCA-based analgesic regimen. Morphine is the most commonly used opioid for pediatric IV-PCA and the dose is based on the child's body weight. The optimum bolus dose (usually $0.02 \mathrm{mg} / \mathrm{kg}$ ) is the minimum dose required to produce satisfactory analgesia without causing significant side effects. Lockout periods should provide sufficient time for the improved analgesia to be noted. Although there is no "correct" or "optimal" lockout period, a range of 5-10 minutes is usually prescribed.

The overall quality of analgesia and the ability to have better sleep quality with less bolus requirements at night 
can be improved by the addition of background infusion to on-demand IV-PCA. Those who object to the addition of this background infusion raise the concern that the use of background infusion may increase the total dose of opioid used, and therefore increase the incidence of opioid-related side effects such as excessive sedation, nausea and respiratory depression without apparent improved pain scores. ${ }^{34}$ However, Yildiz and colleagues reported that by decreasing the bolus dose by $50 \%$, the total opioid (meperidine) consumption was actually lower when a background infusion was added as compared to bolus dosing alone, with no statistical differences in pain, sedation, and nausea scores between the two regimens. ${ }^{35}$

IV-PCA should be available to any child who understands the concept of pushing a button to take away the pain. The maturity of the child, the familiarity with the equipment and hospital environment, the support of the parents, are factors that can encourage early use. Education of the patient and the family about the PCA device is very important before instituting PCA in any pediatric patient. Because of its reasonably long duration of action and mild sedative effect, morphine is the most commonly used opioid for PCA in children. Similar to all other opioids, morphine can also cause nausea, vomiting, pruritus, decrease GI function, and possibly urinary retention. When morphine is contraindicated, or if dose-limiting adverse effects are encountered, fentanyl or hydromorphone can be used. Fentanyl has faster onset and shorter duration than morphine. A background infusion is usually required when dealing with a child with constant pain. In children and adolescents, a small-dose naloxone infusion $(0.25 \mu \mathrm{g} / \mathrm{kg} /$ hour $)$ can significantly reduce the incidence and severity of opioid-induced side effects without affecting opioid-induced analgesia. When initiating morphine IV-PCA for the treatment of moderate to severe pain, clinicians should strongly consider starting a concomitant small-dose naloxone infusion. ${ }^{36}$ However, when dealing with children who may be experiencing intermittent, severe pain of short duration, fentanyl boluses may be particularly effective owing to the rapid onset and short duration of action.

Hydromorphone, with a potency 7 times that of morphine is a hydrogenated ketone of morphine and frequently used as an alternative to morphine in children who are intolerant to morphine. ${ }^{37}$ Although hydromorphone has not been demonstrated to be superior to morphine in terms of analgesic efficacy or side-effect profile, it is frequently chosen in patients with renal problems because it has no active metabolites. The half-life elimination of hydromorphone is 3-4 hours and is typically associated with fewer side effects than morphine (nausea, vomiting, pruritus) and useful in sickle cell patients during the treatment of their pain crises. The addition of NSAID drugs such as ketorolac to morphine IV-PCA regimen has been shown to decrease the morphine requirements and the opioid-related side effects. ${ }^{38}$

\section{Intravenous nurse or parent controlled analgesia in children}

A rather controversial variation on the use of PCA technology in children is that of nurse or parent-assisted PCA also known as NCA and Pr CA. ${ }^{39}$ The technique is controversial because of concerns regarding the risk of overdosage and the potential for respiratory depression if someone other than the patient is allowed to administer bolus doses. Advocates of this approach maintain that it allows young children, and those who are physically or cognitively impaired to receive the same PCA benefits as older children. ${ }^{39}$ Children are started on small-dose continuous opioid infusion. The protocol allows the bolus doses of opioid to be administered by a nurse or parent to treat acute exacerbations of pain. In a series of 240 treatments in 212 patients there was a $1.7 \%$ incidence of apnea and episodes of desaturation requiring treatment with naloxone. ${ }^{40}$ These findings reinforce the need for treatment paradigms and close patient monitoring to minimize the risk and allow for effective intervention when someone other than the patient activates IV-PCA devices.

Nurse-controlled analgesia (NCA) is an alternative suitable and convenient delivery system of controlled drugs by nursing staff that allows them to work around the policies regarding handling of narcotics that can cause delay in pain relief. Using the "PCA" pump, the nurse can immediately administer a pre-calculated and programmed analgesic dose once the assessment of pain is made without leaving the patient's bedside. The use of IV-PCA devices allows timely administration of opioids by the nurse and when appropriately used, it is an excellent patient care convenience and safety initiative. Currently NCA, though not parent assisted analgesia, is a well-established practice and considered to be a generally safe and effective method for delivering opioids to children who are unable to self-administer. Based on documented decreasing bolus demands and ability to tolerate oral fluids, children can be weaned from PCA. If a background infusion is used, it is usually stopped first. The total daily opioid doses prior to weaning can be used to calculate the appropriate equivalent of oral analgesics. There are several causes that can make PCA unsafe. These include improper patient selection, inadequate patient education, unauthorized activation of the PCA device, inadequate staff training and 
errors due to inappropriate prescription, drug dispensing, and PCA pump programming.

\section{Regional anesthesia in children}

In pediatric patients the regional blockade is often used for analgesia in combination with general anesthesia. If the block is placed before the surgical incision (after the anesthetic induction) it can decrease the amount of the narcotics and inhalational agents needed intraoperatively and the side effects of the opioids (nausea, vomiting, hypoventilation, and drowsiness) postoperatively. The regional block can be single shot caudal analgesia or a continuous caudal or epidural block for postoperative analgesia.

There are some important pharmacologic principles of local anesthetics in children that must be kept in mind before administering local anesthetics to young children. ${ }^{41}$ These include the following: (1) there is a potential for toxicity in infants and young children when continuous infusions of local anesthetics are employed because of their prolonged elimination half-lives; (2) local anesthetics lower the seizure threshold; (3) decreased albumin and alpha1-acid glycoprotein serum levels in the young infant can result in less binding of the local anesthetic and thus higher concentrations of the free drug, once again increasing the potential for toxicity.

Maximum recommended doses of local anesthetics for a particular block should be well known prior to administering the drug, whether it is used alone or in combination with epinephrine. Lidocaine $5 \mathrm{mg} / \mathrm{kg}$ may be used alone or up to $7 \mathrm{mg} / \mathrm{kg}$ if lidocaine is used with epinephrine. Bupivacaine has a maximum recommended dose of $2.5 \mathrm{mg} / \mathrm{kg}$ when used alone compared to $3 \mathrm{mg} / \mathrm{kg}$ when combined with epinephrine. It is also very important to avoid the addition of epinephrine to local anesthetics if they are injected into an area of end artery distribution (penis, digit).

\section{Spinal block}

Spinal anesthesia can be used as a sole anesthetic in former preterm infants at risk for postoperative apnea undergoing inguinal hernia repair. It is important to note that the dural sac in the neonate ends at S3 and migrates cephalad to S1 during the first year of life. The procedure is usually done in the sitting position, with neck, chin and the head extended and supported by an assistant to maintain an unobstructed airway.

\section{Epidural/caudal blocks}

The epidural space in a child can easily be reached with a caudal approach without the risk of dural puncture, as compared to an approach via the thoracic or lumbar route. Single-shot caudal analgesia is the most useful and popular pediatric regional block. ${ }^{42}$ Pediatric anesthesiologists with extensive clinical experience attest to the ease of performance, reliability, and safety of the caudal block especially in patients weighing over $10 \mathrm{~kg} .{ }^{43}$ Although caudal block appears simple to perform, one must have respect for the rare and potentially serious complications that can occur with any regional technique. Single-shot caudal blocks are ideally suited for surgical procedures below the level of the umbilicus. ${ }^{44}$ Analgesia for higher dermatomes can be achieved at the expense of a larger volume of local anesthetic or by threading a catheter into the caudal space. This latter method of introducing a catheter through the caudal space in a sterile fashion can allow for continuous infusion or repeated administration of medications, prolonging the analgesia for as long as necessary.

\section{Single-shot caudal analgesia}

The anatomy of the caudal space must be well understood before attempting such a block. The block is placed with the anesthetized patient in the lateral decubitus position after the sacral area is sterilely prepped and the landmarks identified by palpation. The needle is advanced through the sacral hiatus in the midline between the cornua at a 45-degree angle and after the needle pops through the sacrococcygeal ligament, the needle-to-skin angle is reduced so that the needle is advanced $2-3 \mathrm{~mm}$ into the caudal space parallel to the spinal axis.

The three important variables that determine the quality, duration, and extent of a caudal block are volume, total dose, and concentration of the local anesthetic. It is still not very clear whether age or weight is the best criterion for selecting a dose to achieve the desired level of caudal analgesia in children. A study evaluating the correlation of spread of the local anesthetic to age and weight was undertaken by Busoni and Andreuccetti. They noted that both age and weight were predictors of the desired level of analgesia, although weight was a better predictor in newborns and infants and age was a better guide in older children. ${ }^{45}$

Even today the most workable formula for clinical use is the one suggested by Armitage which correlates the level of block with the volume of local anesthetic injected. ${ }^{46}$ In order to achieve a sacral or a T-10 level, the volume is $0.5 \mathrm{~mL} / \mathrm{kg}$ is used, while for a lower to mid-thoracic levels, the volume is 1 and $1.25 \mathrm{~mL} / \mathrm{kg}$ respectively. If there is no opportunity to repeat a single-shot block, the initial dose must be large enough to produce the required level of analgesia. Children 
can become distressed if they cannot feel their legs or move them. Therefore it is important to avoid using concentrations of local anesthetic agents strong enough to cause motor blockade. The maximum dose of bupivacaine recommended is $2.5 \mathrm{mg} / \mathrm{kg}$, which roughly translates to $1 \mathrm{ml} / \mathrm{kg}$ of body weight of the patient when the usual concentration of $0.25 \%$ is used. Therefore it is important to lower the concentration of the bupivacaine from $0.25 \%$ to $0.2 \%$ or even $0.18 \%$ if the volume is to be increased as suggested by Armitage $(1.25 \mathrm{~mL} / \mathrm{kg}$ for mid-thoracic level).

Confirming the effectiveness of the caudal block by testing the level of sensory blockade requires an awake, co-operative, older patient. The anesthesiologist's ability to decrease the concentration of inhaled anesthetic without using opioids during surgery is often considered to indicate a successful caudal block. On the other hand when undergoing hypospadius or orchidopexy or hernia operation under mask administered general anesthesia supplemented with a caudal block, penile erection and tightening of lower abdominal muscles, hyperventilation, vocalization and sympathetic stimulation are physiologic parameters that are evident if the caudal block is inadequate. Another simple test is to confirm the effectiveness of the caudal block in children, is to evaluate the laxity of the patient's anal sphincter by placing an acetaminophen suppository after the block has set in. ${ }^{47}$ The presence of a lax anal sphincter at the end of surgery correlates significantly with the reduced administration of opioids intraoperatively and in the PACU. The presence of a tight sphincter at the end of surgery may suggest an inadequate block, the need to repeat the block before the child awakens, or to consider alternate methods of postoperative analgesia.

The pharmacokinetics of bupivacaine after caudal anesthesia in infants receiving $2.5 \mathrm{mg} / \mathrm{kg}$ of bupivacaine have been studied by Mazoit and colleagues when the serum levels were found to be in the range of $0.5-1.9 \mu \mathrm{g} / \mathrm{mL}$, with peak plasma levels occurring 10-60 minutes after administration. ${ }^{48}$ Eyres and others measured plasma bupivacaine concentrations after caudal injection of $3 \mathrm{mg} / \mathrm{kg}$ of $0.25 \%$ bupivacaine in 45 children whose ages ranged from 4 months to 12 years and found mean blood levels ranging from $1.2-1.4 \mu \mathrm{g} / \mathrm{mL}$, which are well below the limits projected to be toxic in adults. ${ }^{49}$ The peak plasma levels of bupivacaine were less than those considered toxic in adults in all pediatric studies.

Another interesting method to quantitate the duration of caudal analgesia in children was demonstrated by Bromage is by recording the time that elapses before the block level had receded by at least two spinal segments. The duration was found to be 2 hours when bupivacaine was used alone, although slightly longer if an epinephrine-containing local anesthetic solution was used. He also noted that the total duration of action in the lower sacral segments was considerably longer than the time that elapsed before recession began. This observation correlates well with clinical experience, where bupivacaine caudal analgesia, as judged by the time elapsing before the child requires supplemental analgesia, may persist for 4 or 5 hours. $^{50}$

The single-shot caudal block has a significant disadvantage because of its limited duration of action (90-120 minutes with bupivacaine).$^{51}$ Numerous attempts to prolong the analgesic effects of a single-shot caudal block by combining a local anesthetic drug with other additives has been studied by many investigators. Narcotics, the alpha-2 agonists (clonidine, dexmedetomidine), epinephrine, sodium bicarbonate, tramadol, neostigmine, s-ketamine are some of the additives that have been studied and used to prolong and improve the efficacy of the caudal block in children. Addition of preservative free morphine to local anesthetics has been noted to prolong the duration of analgesia after major surgical procedures. ${ }^{51}$ Jamali and others reported on the use of clonidine as an adjunct for pediatric caudal analgesia. They compared bupivacaine alone $(0.25 \%, 1 \mathrm{~mL} / \mathrm{kg})$; with bupivacaine and epinephrine (1:200,000); and with bupivacaine and clonidine $(1 \mu \mathrm{g} / \mathrm{kg})$ for postoperative analgesia. ${ }^{52}$ Adding clonidine to the caudal analgesic mixture was found to more than double the analgesic time. There were no differences in respiratory rate, oxygen saturation values, and hemodynamic parameters or in sedation or sleep time among the three groups. In children undergoing longer surgical procedures below the umbilicus, a repeat caudal block can be done at the end of surgery. If prolonged operative or postoperative analgesia is required, a caudal catheter can be inserted for the administration of either repeated bolus doses or a continuous infusion in pediatric patients undergoing perineal, lower abdominal or lower extremity surgery.

\section{High caudal block}

In children undergoing orchidopexy a higher level of blockade (up to T4) may be necessary to block the peritoneal stimulation arising from spermatic cord traction. Using a higher volume or placing a catheter to reach a higher position and delivering the drug close to the surgical dermatome are the main ways to block a higher segment when a higher level block is necessary.

A high volume aids the spread of the local anesthetic in the epidural space and increases the duration of postoperative analgesia. Increasing the volume of $0.25 \%$ bupivacaine to more than $1 \mathrm{~mL} / \mathrm{kg}$ blocks the signs of the peritoneal 
stimulation although it can result in motor weakness of the lower extremities which becomes significant when epinephrine is added to the bupivacaine solution. Wolf and colleagues compared the efficacy of $0.125 \%$ bupivacaine with that of $0.25 \%$ bupivacaine placed in the caudal space for postoperative analgesia. ${ }^{53}$ Those children who had caudal blocks with $0.125 \%$ bupivacaine at the completion of surgery analgesia was just as effective as that produced by $0.25 \%$ bupivacaine although with less evidence of motor weakness in the postoperative period and thus allowing them to ambulate earlier. It is important to note that the local anesthetic must be diluted with preservative free normal saline solution. The total $\mathrm{mg} / \mathrm{kg}$ dosage should always be checked to ensure that it is within the acceptable safe dose of the drug. In another study of healthy children undergoing orchidopexy at our institution, a caudal block performed with a higher volume of dilute $(0.2 \%)$ bupivacaine was more effective in blocking the peritoneal stimulation during spermatic cord traction than the lower volume of the more concentrated $(0.25 \%)$ solution. A significant point in this study was that the same total dose of local anesthetic was used in all children and there was no change in the quality of postoperative analgesia. ${ }^{54}$ Another prospective, randomized, observer-blind study of children aged 1-5 years-of-age were given a constant dose of $2.25 \mathrm{mg} / \mathrm{kg}$ of ropivacaine solution containing a radiopaque dye either as $1.0 \mathrm{~mL} / \mathrm{kg}$ of $0.225 \%$ (low volume/high concentration) or $1.5 \mathrm{~mL} / \mathrm{kg}$ of $0.15 \%$ solution (high volume/low concentration). The results, confirmed with fluoroscopy, that a caudal block with $1 \mathrm{~mL} / \mathrm{kg}$ ropivacaine spreads to T11 and to T6 with $1.5 \mathrm{~mL} / \mathrm{kg}$ and of that for a total fixed dose, caudal analgesia with a larger volume of diluted ropivacaine $(0.15 \%)$ provides better quality and longer duration after discharge than a smaller volume of more concentrated ropivacaine $(0.225 \%)$ in children undergoing day-case orchiopexy. ${ }^{55}$

\section{Continuous epidural anesthesia}

The most common sites of epidural catheter insertion are (1) caudal (placed via the sacrococcygeal ligament) (2) lumbar and (3) in the thoracic area. Epidural catheter placement allows repeated injections or the use of continuous infusions to provide prolonged blockade. Placing the epidural catheter as close to the dermatome affected by the surgical incision allows the local anesthetics to be placed close to the segments that are necessary to be blocked for adequate pain relief with minimal doses.

\section{Caudal epidural}

The caudal space can be entered by the same technique as in the single shot caudal technique. Instead of a $23 \mathrm{G}$ needle, either a Tuohy or a Crawford epidural needle through the sacrococcygeal membrane can be inserted. The bevel of the needle should be pointed posteriorly in order to advance the catheter easily. After confirming that there is no blood or cerebrospinal fluid on aspiration, the measured length of caudal catheter can be threaded through this needle into the desired location. The advantage of using continuous caudal block with general anesthesia is that it reduces the requirements of intraoperative inhaled anesthetics and opioids lessening the need for postoperative mechanical ventilation especially in neonates and ex-premature infants with pulmonary problems. Caudal epidural anesthesia via a catheter has been used as the sole mode of anesthesia in ex-premature infants having inguinal hernia repair without any postoperative problems. ${ }^{56}$ In a study of 20 premature, high-risk infants undergoing abdominal or thoracic surgery under combined caudal epidural and general anesthesia, epidurography confirmed 17 of the catheters to be in the desired location. However, in 2 patients the catheters were misplaced within the dura, epidural vessel lumen and one was coiled within the epidural space. ${ }^{57}$

Caudal catheters can be advanced cephalad to a high lumbar or thoracic position in infants and children. The catheter should not be forced but smoothly and gently threaded into the desired position and the position of the catheter tip confirmed radiologically.

A study that looked at the efficacy of using the caudal approach to thoracic epidural anesthesia in children showed the catheter tip to be within two vertebrae of the target position by radiologic confirmation in 17 out of 20 children. ${ }^{58}$ The caudal canal has been used successfully to place thoracic epidural catheters by using the electrical nerve stimulation guidance as well as the electrocardiographic guidance in a study of infants. ${ }^{59,60}$ Reports of infection with caudal catheters in children are rare and daily inspection and strict asepsis with tape and clean bio-occlusive barrier dressing of the catheter site is crucial to avoid infection. In a study of 91children, there was an increased incidence of epidural catheter tip colonization reported with the caudal route of insertion, and the bacteria differed from those cultured from the lumbar insertion site. A higher incidence of gram-negative bacteria was cultured from the caudal catheter tips than from the lumbar epidural catheter tips. ${ }^{61}$ Tunneling the catheter under the skin to a higher position has also been used to minimize contamination in some patients who required anesthesia for a prolonged period. ${ }^{62}$ Difficulty in maintaining the catheter insertion site free of fecal contamination has led many pediatric anesthesiologists to place the epidural catheters via the lumbar and thoracic area instead of the caudal area. 


\section{Lumbar epidural}

Continuous lumbar epidurals can be performed successfully in small children. Epidural blockade to T10 (thoracic dermatome corresponding to the umbilicus) provides analgesia for surgery in the lower limb, perineal, urologic and inguinal areas. A higher level up to T4-T6 (thoracic dermatome corresponding to the nipple line) is necessary for abdominal and lower thoracic surgery. Lumbar epidural anesthesia was used intraoperatively and continued for 72 hours for postoperative analgesia in 20 neonates undergoing major thoracoabdominal surgeries. All neonates except one were extubated when awake at the end of the surgery in the operating room and there were no complications from the epidural placement. ${ }^{63}$ Radiological imaging using a dye is very useful with this type of anesthesia in very small infants to confirm the position of the catheter. ${ }^{64}$ A review of epidural anesthesia in 240 neonates showed an incidence of one intravascular migration of catheter, one dural puncture, and one of convulsions. Intraoperative analgesia was effective in all and the majority of these patients had intermittent top-up instead of continuous infusion. ${ }^{65}$

\section{Thoracic epidural}

Placement of thoracic epidural catheters in children should only be done by anesthesiologists who are thoroughly experienced in placing lumbar epidural catheters in children and clearly not by beginners. Experience of the manual skills in placing lumbar epidural catheters in children must be demonstrated before a thoracic epidural placement is considered in an infant. It is also helpful to observe an experienced anesthesiologist place thoracic epidural catheters for pain control during and after extensive thoracoabdominal surgeries in older children and adults before attempting a thoracic epidural in a child or an infant. The spinous processes in the thoracic area are longer, slant downward at a sharper angle and the interspaces are narrower. The introducer needle therefore needs to be angled more cephalad to approach the interspace. Continuous thoracic epidural infusions placed preoperatively (T3-T8 level) have been used in children undergoing pectus repair for intra- and postoperative analgesia with excellent results. ${ }^{66}$ A thoracic epidural blockade is essential for pain control in the perioperative period after the newer minimally invasive repair of the pectus deformity (The Nuss Procedure) where a retrosternal metal bar is placed in the chest thoracoscopically. In this procedure although there is no cartilage resection or osteotomy, the pain from the bar placement is sufficient to warrant a well-established thoracic epidural blockade before surgery and has been used successfully in children as young as 7 years-of-age ${ }^{67}$ In a retrospective review of 220 children undergoing pediatric cardiac surgery under general anesthesia supplemented with regional anesthesia techniques, Peterson and colleagues showed that the use of a thoracic epidural catheter was associated with the lowest incidence of adverse effects. ${ }^{68}$ The safety of insertion and maintenance of thoracic epidural anesthesia in 63 infants and children was reported to be very high with no incidence of dural puncture. ${ }^{69}$ Lumbar and low thoracic catheters can be threaded up to block higher thoracic levels if the site of the operation is higher. However, a very high block (T1-T4) can also result in bradycardia, hypotension and reduced cardiac output by blocking the cardiac sympathetic outflow from the vasomotor center. Unlike adults, epidural catheters are placed in children when they are asleep or deeply sedated and therefore, eliciting paresthesia is not possible. ${ }^{70}$ The risk of spinal cord injury is real and extreme care should be taken to avoid it during a thoracic epidural placement. ${ }^{71}$ In a prospective, randomized study in 64 children $0-6$ years-of-age undergoing major surgery, the ultrasound guidance for epidural catheter placement was compared to the standard or loss-of-resistance (LOR) technique for placing epidural catheters at lumbar or thoracic cord levels. Using a 5-10 MHz linear ultrasound probe, the authors identified the neuraxial structures, measured the skinepidural depth and epidural space, visualized the advancing epidural catheter, and verified the catheter position as well as the spread of local anesthetic. They found that the epidural placement involved bone contacts in only $17 \%$ of children in the ultrasound group compared to the $71 \%$ of children in the LOR group $(P<0.0001)$. Epidurals were also placed more swiftly in the ultrasound group. The authors concluded that ultrasonography is a useful aid to verify epidural placement of local anesthetic agents and epidural catheters in children with advantages that include a reduction in bone contacts, faster epidural placement, direct visualization of neuraxial structures and the spread of local anesthetic inside the epidural space. Although the ultrasound guidance technique is clearly superior, it requires additional training and good manual skills, it should only be used once experience in ultrasound-guided techniques of regional anesthesia has been acquired. ${ }^{72}$

\section{Patient controlled epidural anesthesia}

Older children and teenagers who can understand how to use the PCA devices can be given autonomy over their pain control by allowing them to self administer boluses of local anesthetic if needed for pain relief. This technique, which has become popular in adults, is known as patient controlled epidural anesthesia (PCEA) can be very useful in managing postoperative pain in older children and adolescents. In addition to self-administered 
boluses, a continuous background infusion is always used in PCEA. PCEA is usually used after extensive abdominal, thoracic surgeries (eg, pectus repair), extensive lower limb and spinal surgeries. Orders for the PCEA should have, in addition to the drug concentration (local anesthetic and an opioid, usually fentanyl), volume and basal infusion rate, bolus dose, lockout period and the number of hourly boluses. Since the time needed for a bolus dose to produce a change is longer with epidural compared with IV drug administration the lockout interval is longer, usually 15 minutes compared to 5-8 minutes.

In an earlier study, the efficacy of this modality of pain treatment was evaluated in 128 children, and satisfactory analgesia without serious toxicity or side effects was reported in children as young as 5 years of age. ${ }^{73}$ In another study of 48 children both continuous epidural anesthesia (CEA) and PCEA with $0.2 \%$ ropivacaine provided adequate pain relief in the first 48 hours after orthopedic surgery. However adequate analgesia was obtained with $50 \%$ less volume infused with PCEA as compared with CEA. ${ }^{74}$ This is a potential advantage if the technique is going to be used in a younger patient for a longer period of time. In a recent study, parent-assisted or nurse-assisted epidural analgesia was also found to be safe in children undergoing surgery who are physically or cognitively unable, or unwilling to self-activate a demand dose. ${ }^{75}$

The use of a percutaneously inserted, subcutaneously tunneled epidural catheter for prolonged analgesia in pediatric patients has been found to be safe and an extremely effective method of providing analgesia in children suffering pain from end stage malignancies. ${ }^{76}$

Bupivacaine toxicity and convulsions have occurred in children receiving large doses of bupivacaine via continuous caudal or epidural infusions. When planning to initiate epidural bupivacaine, it has been suggested that after a loading dose of $2-2.5 \mathrm{mg} / \mathrm{kg}$, infusion rates should not exceed a rate of $0.4-0.5 \mathrm{mg} / \mathrm{kg} /$ hour for older infants, toddlers, and children, or $0.2-0.25 \mathrm{mg} / \mathrm{kg}$ per hour for neonates. ${ }^{78}$ Dilute bupivacaine solution $(0.1 \%)$ combined with fentanyl $1-2 \mu \mathrm{g} / \mathrm{mL}$ is commonly used for effective pain control. If the catheter tip is positioned at lumbar or caudal levels for upper abdominal surgery, hydrophilic opioids (eg, morphine or hydromorphone) should be used. Irrespective of the combination of local anesthetics and narcotics, it is crucial to plan for appropriate postoperative monitoring in all the patients after initiating the epidural infusion.

\section{Local anesthetics}

Test dosing is not usually practical or sensitive since most blocks are performed with the children anesthetized or heavily sedated. Detection of accidental intravascular (or intraosseous) injection is extremely difficult. Local anesthetic toxicity is extremely rare in infants and children when the drug dose guidelines are followed and when the procedure is performed by experienced anesthesiologists. However, seizures, dysrhythmias, and cardiovascular collapse have all been reported. Since large volumes are used in caudal and epidural infusions; and because the elimination may be delayed in neonates because of decreased protein binding, there is always a higher risk for toxicity in the younger age group.

\section{Bupivacaine}

Bupivacaine has the worst toxicity profile among the amide local anesthetics and the ratio of the cardiotoxic to the convulsant dose for this drug is lower than that for most other local anesthetics. Despite this well known fact, bupivacaine still remains the most commonly used drug for regional anesthesia in infants and children. The maximum recommended single bolus dose of bupivacaine is $2.5-3.0 \mathrm{mg} / \mathrm{kg}$. The maximum recommended infusion rate for bupivacaine is $0.4-0.5 \mathrm{mg} / \mathrm{kg} /$ hour $(10-2 \mathrm{mg} / \mathrm{kg} /$ day $)$ in older infants and children, and $0.2-0.25 \mathrm{mg} / \mathrm{kg} /$ hour (5 to $6 \mathrm{mg} / \mathrm{kg} / \mathrm{day}$ ) in neonates. Most of the reports of convulsions associated with bupivacaine infusions have occurred during infusions in excess of the recommended limits. Cardiac toxicity from bupivacaine, including myocardial depression and dysrhythmias, can be quite refractory to treatment. The toxic plasma concentration of bupivacaine is $4 \mu \mathrm{g} / \mathrm{mL}{ }^{78}$

The main binding protein for bupivacaine is $\alpha_{1}$-acid glycoprotein. In infants, the presence of free versus bound bupivacaine in the plasma is of critical importance in examining the risk of bupivacaine toxicity. In adults, bupivacaine is approximately $95 \%$ bound to plasma proteins; and only $5 \%$ of the measured bupivacaine concentration is available to produce toxic reactions in the myocardium and central nervous system. Levels of $\alpha_{1}$-acid glycoprotein, and thus bupivacaine free fractions, in older infants and children are comparable to the values seen in adults. However, $\alpha_{1}$-acid glycoprotein levels in neonates and infants younger than 6 months can be less than $50 \%$ of those seen in children and adults, and free bupivacaine concentrations can exceed $20 \%$. Levels of $\alpha_{1}$-acid glycoprotein can be particularly low in premature infants, but increase during early infancy and approach adult values by 6 months of age. ${ }^{79}$

\section{Ropivacaine and levobupivacaine}

Ropivacaine and levobupivacaine are enantiomerically pure compounds rather than racemic mixtures of two 
stereoisomers. They both have anesthetic potency equivalent to bupivacaine while having a lower toxicity and less unwanted motor blockade. ${ }^{80}$ Since they display the same pharmacokinetic profile as racemic bupivacaine with less cardiac toxicity, continuous infusion of these local anesthetics offers the safest therapeutic index, especially in infants.

\section{Ropivacaine}

Ropivacaine produces less motor block than equivalent concentrations of bupivacaine. In addition, ropivacaine undergoes slower absorption from the caudal epidural space in children compared to bupivacaine, which is possibly due to its intrinsic vasoconstrictor properties. It has an anesthetic potency equivalent to bupivacaine and a toxic threshold much higher than that of bupivacaine in animal models. The fatal dose of ropivacaine in sheep has been shown to be almost twice that of bupivacaine ( 7.3 versus $3.7 \mathrm{mg} / \mathrm{kg}$ ). In human volunteers, larger doses of ropivacaine than bupivacaine are tolerated before the development of toxicity symptoms. ${ }^{81}$

Controversies still abound regarding the supposed lower potency of ropivacaine when comparing ropivacaine with bupivacaine in adult studies. In order to obtain an equianalgesic effect, a higher concentration seems to be required thus partially reducing the advantage of lower toxicity and leading to a similar therapeutic ratio. However, this data is different from the pediatric experience where $0.2 \%$ ropivacaine has been demonstrated to have an equianalgesic effect with $0.25 \%$ bupivacaine making the safe therapeutic window wider. $^{82}$

Ropivacaine concentrations used for caudal and epidural anesthesia in children typically range from $0.2 \%-0.25 \%$ in a volume of $1 \mathrm{~mL} / \mathrm{kg}$. Loading doses of $0.2 \%$ ropivacaine for epidural anesthesia in infants and children range from $0.5-0.85 \mathrm{~mL} / \mathrm{kg}$. Caudal or epidural anesthesia with comparable concentrations and volumes of ropivacaine or bupivacaine produces equivalent analgesia. ${ }^{83}$

\section{Levobupivacaine}

Levobupivacaine, the levorotatory enantiomer of racemic bupivacaine has been studied in animal models and has been shown to have a lower toxic potential when compared with dexbupivacaine. The toxicity of levobupivacaine may be intermediate to those of racemic bupivacaine and ropivacaine. Studies of the effects of intravenous infusion of levobupivacaine and racemic bupivacaine in sheep found that convulsions occurred sooner, lasted longer, and required a lower dose after infusion of bupivacaine racemate compared with levobupivacaine. ${ }^{84}$
In adults, the peak plasma concentration of levobupivacaine is approximately $20 \%-25 \%$ greater than that of bupivacaine racemate after either epidural or intravenous administration of identical doses. Despite higher plasma concentrations of levobupivacaine, the plasma concentration of free (unbound) levobupivacaine is lower than that of bupivacaine racemate because of greater protein binding of the levorotatory enantiomer.

\section{Adjunctive agents}

Balancing the efficacy of the anesthetic block with the safety of the patient still remains one of the major challenges in pediatric regional anesthesia. Single injection blocks therefore will not be very popular if a longer duration of analgesia is necessary. One way of increasing the duration and efficacy of the block is to use concentrated local anesthetic solutions in larger volumes, which, can result in unwanted motor blockade. To avoid these problems, various additives have been used in order to improve the quality of caudal blocks without increasing the total dose of the local anesthetic drugs. ${ }^{85}$ It is a well known fact that additives can significantly extend the duration of analgesia. However, what is not yet clear is if this results in improved patient outcome, or outweighs persistent concerns regarding the potential for neurotoxicity of some of the additives. ${ }^{85,86}$

\section{Epinephrine}

The effect of adding epinephrine is less pronounced with bupivacaine than it is with more hydrophilic drugs such as lidocaine. It acts by reducing the systemic uptake of the local anesthetic drugs and through its alpha-2 adrenergic stimulating properties, enhances the duration and quality of both peripheral and neuraxial blocks. Most commercially premixed epinephrine-containing local anesthetic solutions have a lower $\mathrm{pH}$ than plain solutions and this lower $\mathrm{pH}$ may delay the uptake of the drug across neural membranes. ${ }^{87}$

\section{Sodium bicarbonate}

It has been demonstrated in previous studies that the elevation of the $\mathrm{pH}$ of local anesthetics results in a more rapid onset of action and enhanced quality and duration of the anesthetic block. ${ }^{88}$ The addition of $0.1 \mathrm{~mL}$ of a standard $8.4 \%$ solution of sodium bicarbonate to a $20 \mathrm{~mL}$ solution of $0.25 \%$ bupivacaine will raise the $\mathrm{pH}$ of the local anesthetic from 5.49 to 7.04 . This simple approach is particularly useful when commercial epinephrine-containing bupivacaine with a low $\mathrm{pH}$ is used, or to enhance the effect of a very dilute solution of bupivacaine. 


\section{Neuraxial opioids}

Administration of opioids neuraxially results in excellent and longer lasting analgesia. When delivered at the epidural or spinal site, the opioids bypass the blood brain barrier and require significantly less (1/10-1/100th) dose to be effective. However, whether the opioid is administered via the caudal, epidural, or spinal routes, delayed respiratory depression is a potential problem especially in young infants; and when there is the concomitant administration of systemic opioids. Hydrophilic opioids (eg, morphine or hydromorphone) can be administered through lumbar or caudal catheters. With these opioids, a wider range of dermatomes can be covered after caudal or lumbar catheter placement and only small increases in dose are required for a surgical site remote from the catheter tip. This same characteristic, unfortunately, also appears to increase the risk for side effects including respiratory depression as a result of the rostral spread of morphine in the cerebrospinal fluid to the central respiratory center in the brainstem. Hydromorphone may also offer some advantages because there is less rostral spread when administered by the epidural route and slightly less pruritus than with morphine; although it provides more rostral spread than with fentanyl. Lumbar administration spreads sufficiently to provide thoracic analgesia. It should be noted that the potency of hydromorphone relative to morphine in the epidural space is less than when it is administered systemically (2-3:1 epidural versus $5: 1$ systemic). ${ }^{1}$ Other side effects that can be distressing include vomiting, urinary retention, postoperative ileus, and pruritus. Thus neuraxial administration of opioids requires specific routines and protocols for their safe use in children. In children following open heart surgery, Rosen and colleagues demonstrated that administering caudal epidural morphine was an effective mode of treatment of postoperative pain. ${ }^{89}$

\section{Alpha-2-agonists Clonidine}

Clonidine acts in the brain and spinal cord by stimulating alpha-2 inhibitory neurons in the vasomotor center, creating a reduction in the sympathetic outflow to the tissues. The addition of the alpha-2 agonist clonidine to local anesthetic solutions has been shown to enhance the duration and quality of central and peripheral nerve blocks. When administered into the spinal or epidural space, clonidine acts presynaptically at C-fibers and postsyaptically on dorsal horn neurons through a G-1 coupled $\mathrm{K}^{+}$channel and leads to spinal analgesia and decreased central sensitization. ${ }^{90}$

Clinically, the addition of clonidine $(1-2 \mu \mathrm{g} / \mathrm{kg})$ to a single injection bolus of a local anesthetic has been consistently shown to substantially prolong the duration of the caudal blockade. The addition of clonidine in doses of approximately $0.1 \mu \mathrm{g} / \mathrm{kg} /$ hour significantly enhances the analgesic quality of continuous epidural infusions. The main advantage of clonidine (compared to the opioids) is the negligible risk of respiratory depression. In addition the higher incidence of mild-to-moderate sedation with clonidine is actually advantageous following major surgery in hospitalized children although not desirable in ambulatory patients.

\section{Dexmedetomidine}

Dexmedetomidine hydrochloride $\left(\right.$ Precedex $^{\circledR}$ ), a compound derived from imidazole, is a potent and highly selective (8 times higher than clonidine) alpha2-adrenoreceptor agonist. The addition of clonidine or dexmedetomidine to bupivacaine prolongs caudal analgesia in children. ${ }^{91}$ Dexmedetomidine is known to have sedative, hypnotic and analgesic properties. It diminishes the need for other anesthetics and sympatholytics, and it reduces the release of catecholamine. The site of action for the sedative action of this drug is considered to be the locus coeruleus. Caudally administered dexmedetomidine $(1 \mu \mathrm{g} / \mathrm{kg})$, combined with bupivacaine was studied in children ages 1-6 years-of-age undergoing unilateral hernia repair and the results showed an extended duration of postoperative pain relief. ${ }^{92}$ Caudal dexmedetomidine seems to be a promising adjunct to provide excellent analgesia without side effects over a 24 hour period. Dexmedetomidine has the added advantage of keeping the patients calm for a prolonged time.

\section{S-ketamine}

The analgesic effect of caudal administered ketamine is believed to result from the interaction with NMDA or opioid receptors at the spinal level. As with clonidine, the main advantage of using epidural ketamine is the lack of respiratory depression. Using a bolus dose of up to $1 \mathrm{mg} / \mathrm{kg}$ of caudal or epidural preservative free ketamine the risk of psychological side effects appears to be low. Thirty children (ASA I-II, 1 month-9 years) scheduled for minor inguinal or penile surgery, were randomly assigned in a prospective, double-blind fashion to receive single shot caudal blockade by either bupivacaine $0.125 \% 1 \mathrm{~mL} / \mathrm{kg}$ or a mixture of bupivacaine $0.125 \% 1 \mathrm{~mL} / \mathrm{kg}$ and preservative free s-ketamine $0.5 \mathrm{mg} / \mathrm{kg}$. The addition of $0.5 \mathrm{mg} / \mathrm{kg}$ of preservative free s-ketamine to caudal bupivacaine $(0.125 \%$ at $1 \mathrm{~mL} / \mathrm{kg}$ ) provided a significant prolongation of analgesia without producing negative side-effects. ${ }^{93}$

Another study looked at the addition of $0.5 \mathrm{mg} / \mathrm{kg}$ $\mathrm{s}(+)$-ketamine to levobupivacaine $0.175 \%$ for caudal 
analgesia in lower abdominal and urological surgery and found that the addition of $s(+)$-ketamine was significantly more effective in providing postoperative analgesia than levobupivacaine $(0.15 \%)$ with $0.5 \mathrm{mg} / \mathrm{kg} \mathrm{s}(+)$-ketamine or $0.2 \%$ levobupivacaine alone. ${ }^{94}$

\section{Neostigmine}

Analgesia and the side-effects associated with caudal neostigmine, co-administered with bupivacaine for pediatric surgery has been studied and have concluded that caudal neostigmine, when given in a dose of $20-50 \mu \mathrm{g} / \mathrm{kg}$, provides dose dependent analgesia. However, doses exceeding $30 \mu \mathrm{g} / \mathrm{kg}$ are associated with a higher incidence of nausea and vomiting. ${ }^{95}$ A single caudal injection of neostigmine $2 \mu \mathrm{g} / \mathrm{kg}$ combined with $0.2 \%$ ropivacaine offers an advantage over ropivacaine alone for postoperative pain relief in preschool children undergoing genitourinary surgery. ${ }^{96}$

\section{Tramadol}

The addition of tramadol to bupivacaine for caudal epidural block in children significantly prolongs the duration of postoperative analgesia. Tramadol, a synthetic analogue of codeine, is a racemic mixture of two enantiomers; $(+)$ tramadol and (-) tramadol and is a unique analgesic with mu-1 agonist activity. The (+) enantiomer has a moderate affinity for the opioid $\mu$-receptor and also inhibits serotonin uptake, while the (-)-enantiomer is a potent norepinephrine inhibitor. These complementary properties result in an opioid with an analgesic potency approximately equal to that of meperidine, but without any respiratory depressant effect.

Caudal tramadol $2 \mathrm{mg} / \mathrm{kg}$, combined with bupivacaine $(0.25 \%$ at $0.75 \mathrm{~mL} / \mathrm{kg})$ provided longer duration of postoperative analgesia and reduced the requirement for rescue analgesia compared with tramadol $1 \mathrm{mg} / \mathrm{kg}$ or $1.5 \mathrm{mg} / \mathrm{kg}$ in 80 children (2-8 years-of-age) undergoing inguinal herniotomy. ${ }^{97}$ Another study of 75 children, aged between 3 and 9 years showed that caudally administered $0.25 \%$ bupivacaine (at $0.5 \mathrm{~mL} / \mathrm{kg}$ ) plus ketamine or $0.25 \%$ bupivacaine plus tramadol (at $1 \mathrm{mg} / \mathrm{kg}$ ) provided significantly longer analgesia without an increase in the adverse effects when compared to bupivacaine alone..$^{98}$

\section{Midazolam}

A prospective, randomized, double-blind study aimed to determine whether caudal midazolam combined with ropivacaine affects anesthetic requirements, recovery profiles, and postoperative analgesia, compared with ropivacaine alone, was recently undertaken with 60 boys aged between $2-5$ years. Caudal midazolam $(50 \mu \mathrm{g} / \mathrm{kg})$ added to $2 \%$ ropivacaine (at $1 \mathrm{~mL} / \mathrm{kg}$ ) with epinephrine 1:200,000 was found to provide improved postoperative analgesia when compared with $2 \%$ ropivacaine with epinephrine 1:200,000 alone in these young children undergoing hernia repair in a pediatric ambulatory setting. ${ }^{99}$

\section{Summary}

Effective postoperative analgesia in infants and young children continues to evolve with innovative methods of therapy using newer drugs or older drugs introduced via novel routes. Age appropriate pain assessment tools continue to be critically evaluated, validated and improved as one of the most critical components of pain management. A multimodal approach to preventing and treating pain is usually used to minimize the side effects of individual drugs or techniques. ${ }^{100}$ Regional analgesia must be considered unless contraindicated. Bupivacaine, a long acting wellstudied local anesthetic is most commonly used in children. Both ropivacaine and levobupivacaine may find their use, in neonates, in patients with impaired hepatic function where prolonged infusions are needed and for anesthetic techniques requiring a large mass of a local anesthetic drug. Ultrasonography guidance blocks will probably become the reference technique for local anesthetic injections and regional anesthesia catheter placement; which will benefit from new training in this field. ${ }^{101,102}$

Finally, a well-organized pediatric pain service which includes well trained pediatric anesthesiologists who can teach the trainees daily and act as pain consultants to the other departments of the hospital together with a group of equally committed and specially trained nursing staff is essential for the successful management of acute pain in infants and children.

\section{Disclosure}

The authors report no conflicts of interest in this work.

\section{References}

1. Malviya S, Polaner DM, Berde C. Acute pain. In: Cote CJ, Lerman J, Todres ID, editors. A practice of anesthesia for infants and children. Philadelphia: Saunders Elsevier; 2009. p. 939-978.

2. Verghese ST, Hannallah RS. Postoperative Pain Management in Children. Anesthesiology Clinics N Am. 2005;23:163-184.

3. O'Rouke D. The measurement of pain in infants, children, and adolescents: from policy to practice. Phys Ther. 2004; 84:560-570.

4. Voepel-Lewis T, Merkel S, Tait AR, et al. The reliability and validity of the Face, Legs, Activity, Cry, Consolability observational tool as a measure of pain in children with cognitive impairment. Anesth Analg. 2002;95(5):1224-1229. 
5. Birmingham PK, Tobin MJ, Fisher DM, et al. Initial and subsequent dosing of rectal acetaminophen in children- a 24-hour pharmacokinetic study of new dose recommendations. Anesthesiology. 2001;94: 385-389.

6. Montgomery CJ, McCormack JP, Reichert CC, et al. Plasma concentrations after high-dose (45 mg.kg-1) rectal acetaminophen in children. Can J Anaesth. 1995; 42:982-986.

7. Berde CB, Sethna NF. Analgesics for the treatment of pain in children. N Engl J Med. 2002;347:1094-1103.

8. Anderson BJ, Holford NH, Woollard GA, et al. Perioperative pharmacodynamics of acetaminophen analgesia in children. Anesthesiology. 1999;90:411-421.

9. Romsing J, Hertel S, Harder A, et al. Examination of acetaminophen for outpatient management of postoperative pain in children. Paediatr Anaesth. 1998;8:235-239.

10. Bremerich DH, Neidhart G, Heimann K, et al. Prophylacticallyadministered rectal acetaminophen does not reduce postoperative opioid requirements in infants and small children undergoing elective cleft palate repair. Anesth Analg. 2001;92:907-912.

11. Hannallah RS. "Outpatient Anesthesia". In: Coté C, Todres ID, editors. A practice of anesthesia for infants and children. Philadelphia: WB Saunders; 2001. p. 55-67.

12. Heubi JE, Barbacci MB, Zimmerman HJ. Therapeutic misadventures with acetaminophen: hepatotoxicity after multiple doses in children. J Pediatr. 1998;132:22-27.

13. Capici F, Ingelmo PM, Davidson A, et al. Randomized controlled trial of duration of analgesia following intravenous or rectal acetaminophen after adenotonsillectomy in children. Br J Anaesth. 2008; 100:251-255.

14. Pickering AE, Bridge HS, Nolan J, et al. Double-blind, placebo-controlled analgesic study of ibuprofen or rofecoxib in combination with paracetamol for tonsillectomy in children. Br J Anaesth. 2002;88: 72-77.

15. Joshi W, Connelly NR, Reuben SS, et al. An evaluation of the safety and efficacy of administering rofecoxib for postoperative pain management. Anesth Analg. 2003;97:35-38.

16. Malmberg AB, Yaksh TL. Hyperalgesia mediated by spinal glutamate or substance P receptor blocked by spinal cyclooxygenase inhibition. Science. 1992;257:1276-1279.

17. van der Marel CD, Anderson BJ, Romsing J, et al. Diclofenac and metabolite pharmacokinetics in children. Paediatr Anaesth. 2004; $14: 443-451$.

18. Hall SC. Tonsillectomies, ketorolac, and the march of progress. Can J Anaesth. 1996;43:544-548.

19. Chamie K, Chi A, Hu B, et al. Contemporary open ureteral reimplantation without morphine: assessment of pain and outcomes $J$ Urol. 2009;182(3):1147-1151.

20. Park JM, Houck CS, Sethna NF, et al. Ketorolac suppresses postoperative bladder spasms after pediatric ureteral reimplantation. Anesth Analg. 2000;91:11-15.

21. Splinter WM, Rhine EJ, Roberts DW, et al. Ketorolac tromethamine increases bleeding after tonsillectomy in children. Can J Anaesth. 1996;43:560-563.

22. Marret E, Flahault A, Samama C-M, et al. Effects of postoperative, nonsteroidal, anti-inflammatory drugs on bleeding risk after tonsillectomy. Anesthesiology. 2003;98:1497-1502.

23. Moiniche S, Romsing J, Dahl JB, et al. Nonsteroidal anti-inflammatory drugs and the risk of operative site bleeding after tonsillectomy: a quantitative systemic review. Anesth Analg. 2003;96: 68-77.

24. Dawson GS, Seidman P, Ramadan HH. Improved postoperative pain control in pediatric adenotonsillectomy with dextromethorphan. Laryngoscope. 2001;111:1223-1226.

25. Rose JB, Guy R, Cohen DE, et al. Preoperative oral dextromethorphan does not reduce pain or analgesic consumption in children after adenotonsillectomy. Anesth Analg. 1999;88: 749-753.
26. Ali SM, Shahrbano S, Ulhaq TS. Tramadol for pain relief in children undergoing adenotonsillectomy: a comparison with dextromethorphan Laryngoscope. 2008;118(9):1547-1549.

27. Finkel JC, Rose JB, Schmitz ML, et al. An evaluation of the efficacy and tolerability of oral tramadol hydrochloride tablets for the treatment of post surgical pain in children. Anesth Analg. 2002;94:469-473.

28. Engelhardt T, Steel E, Johnston G, et al. Tramadol for pain relief in children undergoing tonsillectomy: a comparison with morphine. Paeditric Anaesth. 2003;13:249-252.

29. Courtney MJ, Cabraal D. Tramadol vs diclofenac for post-tonsillectomy analgesia. Arch Otolaryngol Head Neck Surg. 2001;127:385-388.

30. Arcioni R, Rocca MD, Romano S, et al. Ondansetron inhibits the analgesic effects of tramadol: a possible $5-\mathrm{HT}_{3}$ spinal receptor involvement in acute pain in humans. Anesth Analg. 2002;94: 1553-1557.

31. Semple D, Russell S, Doyle E, et al. Comparison of morphine sulphate and codeine phosphate in children undergoing adenotonsillectomy. Paeditric Anaesth. 1999;9:135-138.

32. Galinkin JL, Fazi LM, Cuy RM, et al. Use of intranasal fentanyl in children undergoing myringotomy and tube placement during halothane and sevoflurane anesthesia. Anesthesiology. 2000;93:1378-1383.

33. Finkel JF, Cohen IT, Hannallah RS, et al. The effect of intranasal fentanyl on the emergence characteristics after sevoflurane anesthesia in children undergoing surgery for bilateral myringotomy tube placement. Anesth Analg. 2001;92:1164-1168.

34. Peters JWB, Hoekstra B IENG, Abu-Saad HH, et al. Patient controlled analgesia in children and adolescents: a randomized controlled trial. Paeditric Anaesth. 1999;9:235-241.

35. Yildiz K, Tercan E, Dogru K, et al. Comparison of patient-controlled analgesia with and without a background infusion after appendectomy in children. Paeditric Anaesth. 2003;13:427-431.

36. Maxwell LG, Kaufmann SC, Bitzer S, et al. The effects of a smalldose naloxone infusion on opioid induced side effects and analgesia in children and adolescents treated with intravenous patient-controlled analgesia: a double-blind, prospective, randomized, controlled study. Anesth Analg. 2005;100:953-958.

37. McDonald AJ, Cooper MG. Patient-controlled analgesia - an appropriate method for pain control in children. Pediatric Drugs. 2001;3:273-284.

38. Sutter KA, Shaw BA, Gerardi JA, et al. Comparison of morphine patient-controlled analgesia with and without ketorolac for postoperative analgesia in pediatric orthopedic surgery. Am J Orthop. 1999;28:351-358.

39. Monitto CL, Greenberg RS, Kost-Byerly S, et al. The safety and efficacy of parent-/nurse-controlled analgesia in patients less than six years of age. Anesth Analg. 2000;91:573-579.

40. Kanagasundaram SA, Cooper MG, Lane LJ. Nurse-controlled analgesia using a patient-controlled analgesia device: an alternative strategy in the management of severe cancer pain in children. J Paediatr Child Health. 1997;33:352-355.

41. Berde CB. Toxicity of local anesthetics in infants and children J Pediatr. 1993;122:S14-20.

42. Rice LJ, Hannallah RS. Pediatric Regional Anesthesia. In: Motoyama EK, editor. Smith's anesthesia for infants and children. St. Louis: Mosby; 1990. p. 393-425.

43. Dalens B, Hasnouai A. Caudal anesthesia in pediatric surgery-success rate and adverse effects in 750 consecutive patients. Anesth Analg. 1989;68:83-86.

44. Hannallah RS, Broadman LM, Belman AB, et al. Comparison of Caudal and Ilioinguinal/Iliohypogastric Nerve Blocks for Control of Post-orchiopexy pain in Pediatric Ambulatory Surgery. Anesthesiology. 1987;66:832-834.

45. Busoni P, Andreuccetti T. The spread of caudal analgesia in children-a mathematical model. Anaesth Intens Care. 1986;14: $140-144$.

46. Armitage EN. Local anesthetic techniques for prevention of postoperative pain. Br J Anaesth. 1986;58:790-800. 
47. Verghese S, Mostello L, Patel RI, et al. Testing the anal sphincter tone predicts the effectiveness of caudal analgesia in children. Anesth Analg. 2002;94:1161-1164.

48. Mazoit JX, Denson DD, Samii K. Pharmacokinetics of bupivacaine following caudal anesthesia in infants. Anesthesiology. 1988;68: 387-391.

49. Eyres RL, Hastings C, Brown TCK. Plasma bupivacaine concentrations in children during caudal epidural analgesia. Anaesth Intensive Care. 1983;11:20-22.

50. Bromage PR. Aging and epidural dose requirements. Br J Anaesth. 1969;41:1016-1022.

51. Krane EJ, Jacobson LE, Lynn AM, et al. Caudal morphine for postoperative analgesia in children: A comparison with caudal bupivacaine and intravenous morphine. Anesth Analg. 1987;66: 647-653.

52. Jamali S, Monin S, Begon C, et al. Clonidine in pediatric caudal anesthesia. Anesth Analg. 1994;78:663-666.

53. Wolf AR, Valley RD, Fear DW, et al. Bupivacaine for caudal analgesia in infants and children: the optimal effective concentration. Anesthesiology.1988;69:102-106.

54. Verghese S, Hannallah R, Rice L, et al. Caudal anesthesia in children: effect of volume vs concentration of bupivacaine in blocking spermatic cord traction response during orchidopexy. Anesth Analg. 2002; 95:1219-1224

55. Hong JY, Han SW, Kim WO, et al. A Comparison of high volume/ high concentration ropivacaine in caudal analgesia for pediatric orchidopexy. Anesth Analg. 2009;109:1073-1078.

56. Tobias JD, Rasmussen GE, Holcomb GW III, et al. Continuous caudal anesthesia with chloroprocaine as an adjunct to general anesthesia in neonates. Can J Anaesth. 1996;43:69-72.

57. van Nierck J, Bax- Vermeire BM, Geurts JW, et al. Epidurography in premature infants. Anesthesia. 1990;45:722-725.

58. Gunter GB, Eng C. Thoracic epidural anesthesia via the caudal approach in children. Anesthesiology. 1992;76:935-938.

59. Tsui BC, Tarkkila P, Gupta S, et al. Confirmation of caudal needle placement using nerve stimulation. Anesthesiology. 1999;91:374-378.

60. Tsui BCH, Seal R, Koller J. Thoracic epidural catheter placement via the caudal approach in infants by using electrocardiographic guidance. Anesth Analg. 2002;95: 326-330.

61. Mc Neely JK, Trentadue NC, Rusy LM, et al. Culture of bacteria for lumbar and caudal epidural catheters used for postoperative analgesia in children. Reg Anesth Pain Med. 1997;22:428-431.

62. Bubeck J, Boos K, Krause H, et al. Subcutaneous tunneling of caudal catheters reduces the rate of bacterial colonization to that of lumbar epidural catheters. Anesth Analg. 2004;99:689-693.

63. Vas L, Naregal P, Sanzgiri S, et al. Some vagaries of neonatal lumbar epidural anesthesia. Paediatr Anaesth. 2000;10:114-115.

64. Valairucha S, Seefelder C, Houck CS, et al. Thoracic epidural catheters placed by the caudal route in infants: the importance of radiographic confirmation. Paediatric Anaesth. 2002;12:424-428.

65. Bosenberg AT. Epidural analgesia for major neonatal surgery. Paediatric Anaesth. 1998;8:114-115.

66. McBride WJ, Dicker R, Abajian JC, et al. Continuous thoracic epidural infusions for postoperative analgesia after pectus deformity repair. J Pediatr Surg. 1996;31:105-107.

67. Fukunaga T, Kitamura S, Kinouchi K, et al. Anesthetic management for the correction of pectus excavatum using pectus bar under videoassistance. Masui J Anesthesiology. 2001;50:171-174.

68. Peterson KL, De Campil WM, Pike NA, et al. A report of 220 cases of regional anesthesia in pediatric cardiac surgery. Anesth Analg. 2000; 90:1014-1019.

69. Tobias JD, Lowe S, O' Dell N, et al. Thoracic epidural anesthesia in infants and children. Can J Anaesth. 1993;40:810-812.

70. Krane EJ, Dalens BJ, Murat I, et al. The safety of epidurals placed during general anesthesia. Reg Anesth Pain Med. 1998;23: 433-438.
71. Kasai T, Yaegashi K, Hirose M, et al. Spinal cord injury in a child caused by an accidental dural puncture with a single-shot thoracic epidural needle. Anesth Analg. 2003;96:65-67.

72. Willschke H, Marhofer P, Bosenberg A, et al. Epidural Catheter placement in Children: comparing a novel approach using ultrasound guidance and a standard loss-of-resistance technique. Br J Anaesth. 2006;97:200-207.

73. Arms DM, Smith JT, Osteyee J, et al. Postoperative analgesia for pediatric spine surgery. Orthopedics. 1998;21:539-544.

74. Birmingham PK, Wheeler M, Suresh S, et al. Patient Controlled Epidural Analgesia in children: can they do it? Anesth Analg. 2003; 96:686-691.

75. Antok E, Bordet F, Duflo F, et al. Patient- controlled epidural analgesia versus continuous epidural infusion with ropivacaine for postoperative analgesia in children. Anesth Analg. 2003;97:1608-1611.

76. Birmingham PK, Suresh S, Ambrosy A, et al. Parent-assisted or nurse-assisted epidural analgesia: is this feasible in pediatric patients? Paediatr Anaesth. 2009;11:1084-1089.

77. Aram L, Krane EJ, Kozloski LJ, et al. Tunneled epidural catheters for prolonged analgesia in pediatric patients. Anesth Analg. 2001;92:1432-1438.

78. Berde CB. Convulsions associated with pediatric regional anesthesia. Anesth Analg. 1992;75:164-166.

79. Lerman J, Strong HA, Le Dez KM, et al. Effects of age on the serum concentration of alpha-1 acid glycoprotein and the binding of lidocaine in pediatric patients. Clin Pharmacol Ther. 1989;46:219-225.

80. De Negri P, Ivani G, Tirri T, et al. A comparison of epidural bupivacaine, levobupivacaine, and ropivacaine on postoperative analgesia and motor blockade. Anesth Analg. 2004;99:45-48.

81. Nancarro C, Rutten AJ, Runciman WB, et al. Myocardial and cerebral drug concentrations and the mechanisms of death after fatal intravenous doses of lidocaine, bupivacaine, and ropivacaine in the sheep. Anesth Analg. 1989;69:276-283.

82. Ivani G. Ropivacaine: is it time for children? Paediatr Anaesth. 2002;12:383-387.

83. Gunter JB. Benefits and risks of local anesthetics in infants and children. Pediatric Drugs. 2002;4:649-672.

84. Huang YF, Pryor ME, Mather LE, et al. Cardiovascular and central nervous system effects of intravenous levobupivacaine and bupivacaine in sheep. Anesth Analg. 1998;86:797-804.

85. Ansermino MK, Basu R, Vandebeek C, et al. Nonopioid additives to local anesthetics for caudal blockade in children: a systematic review. Paeditric Anesthesia. 2003;13:561-573.

86. de Beer DAH, Thomas ML. Caudal additives in children-solutions or problems? Br J Anaesth. 2003;90:487-498.

87. Robinson J, Fernando R, Sun Wai WY, et al. Chemical stability of bupivacaine, lidocaine and epinephrine in $\mathrm{pH}$-adjusted solutions. Anesthesia. 2000;55:853-858.

88. Capogna G, Celleno D, Laudano D, et al. Alkalinization of local anesthetics. Which block which local anesthetic? Reg Anesth Pain Med. 1995;20:369-377.

89. Rosen KR, Rosen DA. Caudal epidural morphine for control of pain following open-heart surgery in children. Anesthesiology. 1989;70:418-421.

90. Eisenach JJC, De Kock MM, Klimscha WM. Alpha sub 2-adrenergic agonists for regional anesthesia: a clinical review of clonidine. (1964-1995) Anesthesiology. 1996;85:655-674.

91. El- Hennawy, Abd- Elwahab AM, Abd Elmaksoud AM, et al. Addition of clonidine or dexmedetomidine to bupivacaine prolongs caudal analgesia in children. Br J Anaesth. 2009;103:268-274.

92. Saadawy I, Boker A, Elshahawy MA, et al. Effect of dexmedetomidine on the characteristics of bupivacaine in a caudal block in pediatrics. Acta Anaesthesiol Scand. 2009;53:251-256.

93. Weber F, Wulf H. Caudal bupivacaine and $\mathrm{S}(+)$-ketamine for postoperative analgesia in children. Paediatric Anaesth. 2003;13: 244-248. 
94. Locatelli BG, Frawley G, Spotti A, et al. Analgesic effectiveness of caudal levobupivacaine and ketamine. Br J Anaesth. 2008;100:701-706.

95. Batra YK, Arya VK, Mahajan R, et al. Dose response study of caudal neostigmine for postoperative analgesia in paediatric patients undergoing genitourinary surgery. Paediatr Anaesth. 2003;13: 515-521.

96. Turan A, Memis D, Basaran UN, et al. Caudal ropivacaine and neostigmine in pediatric surgery. Anesthesiology. 2003;98:719-722.

97. Prakash S, Tyagi R, Gogia AR, et al. Efficacy of three doses of tramadol with bupivacaine for caudal analgesia in paediatric inguinal herniotomy. Br J Anaesth. 2006;97(3):385-358.

98. Choudhuri AH, Dharmani P, Kumari N, et al. Comparison of caudal epidural bupivacaine with bupivacaine plus tramadol and bupivacaine plus ketamine for postoperative analgesia in children. Anaesth Intensive Care. 2008;36:174-179.
99. Hong JY, Lee IH, Shin SK, et al. Caudal midazolam does not affect sevoflurane requirements and recovery in pediatric day-case hernioplasty. Acta Anaesthesiol Scand. 2008;52:1411-1414.

100. Verghese ST. Caudal/Epidural Anesthesia in Children: Parts 1 and 2. In: Eisenkraft JB, editor. Progress in Anesthesiology. San Antonio: Dannemiller Memorial Educational Foundation; 2004. p. 99-108 and 127-136.

101. Weintraud M, Marhofer P, Bosenberg A, et al. Ilioinguinal/ Iliohypogastric blocks in children: Where do we administer the local anesthetic without direct visualization? Anesth Analg. 2008;106: 89-93.

102. Ecoffey C. Pediatric Regional Anesthesia.-Update. Curr Opin Anaesthesiol. 2007;20:232-235.
Journal of Pain Research

\section{Publish your work in this journal}

The Journal of Pain Research is an international, peer-reviewed, open access, online journal that welcomes laboratory and clinical findings in the fields of pain research and the prevention and management of pain. Original research, reviews, symposium reports, hypothesis formation and commentaries are all considered for publication.

\section{Dovepress}

The manuscript management system is completely online and includes a very quick and fair peer-review system, which is all easy to use. Visit http://www.dovepress.com/testimonials.php to read real quotes from published authors. 